\title{
Os desafios de traduzir o humor político para o português: escolhas tradutórias para Tutta Casa, Letto e Chiesa, de Franca Rame e Dario Fo
}

\section{The challenges of translating political humor into Portuguese: translation choices for Tutta Casa, Letto and Chiesa by Franca Rame e Dario Fo}

Amanda Bruno de Mello ${ }^{1}$

${ }^{1}$ Amanda Bruno de Mello é mestre em Letras: Estudos Literários pelo Pós-Lit/UFMG e doutoranda na mesma instituição, com bolsa CAPES. E-mail: amanda.bruno.mello@gmail.com

$$
\begin{gathered}
\text { TradTerm, São Paulo, v.38, fevereiro/2021, p. 81-90 } \\
\text { Número Especial - III JOTA } \\
\text { www.revistas.usp.br/tradterm }
\end{gathered}
$$


Resumo: A peça Tutta Casa, Letto e Chiesa (1977) de Franca Rame e Dario Fo, é uma peça composta por seis monólogos para uma atriz, escrita em um período de grande polarização política na Itália. Seu fio condutor é a condição da mulher, assim como a luta por maior igualdade. Os monólogos possuem um tom cômico, elementos épicos e relação com o contexto político italiano da época. Traduzi-los para o português foi desafiador por vários motivos, muitos dos quais se relacionam ao dilema de conciliar elementos antagônicos: o espectador deve ter certa familiaridade com os temas tratados para que o riso possa acontecer, como teoriza Bergson (2020); além da importância de manter, na tradução, as referências ao contexto político em que o espetáculo foi escrito. Este trabalho analisa três situações em que esse dilema se manifestou, apresenta as escolhas tradutórias tomadas e suas justificativas.

Palavras-chave: Tradução; Teatro; Dario Fo e Franca Rame; Humor, Tutta Casa, Letto e Chiesa.

Abstract: The play Tutta Casa, Letto e Chiesa (1977) by Franca Rame and Dario Fo is composed by six monologues for an actress, written in a period of great political polarization in Italy. Its guiding thread is the condition of women, as well as the struggle for greater equality. The monologues have a comic tone, epic elements and are related to the Italian political context of the time. Translating them into Portuguese was challenging for several reasons, many of which can be grouped in the dilemma of reconciling antagonistic elements: the viewer must have at least a certain familiarity with the themes treated so that laughter can happen, as theorized Bergson (2020); beyond the importance of maintaining, in translation, the references to the political context. This paper analyzes three situations in which this dilemma manifested itself, presents the translation choices and its justifications.

Keywords: Translation; Theater; Dario Fo and Franca Rame; Humor, Tutta Casa, Letto e Chiesa.

TradTerm, São Paulo, v.38, fevereiro/2021, p. 81-90

Número Especial - III JOTA

www.revistas.usp.br/tradterm 
Dario Fo recebeu o prêmio Nobel em 1997, "seguindo a tradição dos jograis medievais, zombar do poder, restituindo a dignidade aos oprimidos". ${ }^{2}$ Franca Rame, sua maior colaboradora e esposa, não foi agraciada, mas, segundo o autor italiano, esse é um prêmio para a obra conjunta do casal. A justificativa para a entrega do prêmio dá conta de dois dos principais traços da poética da obra de Rame e Fo, o humor e a luta política, vinculados: o humor é uma ferramenta para estimular a capacidade crítica da plateia e, portanto, está a serviço da emancipação.

0 teatro italiano é um teatro político, pedagógico; por isso, associado aos eventos políticos ou sociais da época em que as peças foram escritas. Em particular, no caso de Tutta Casa, Letto e Chiesa, é impossível dissociar o espetáculo das discussões e das lutas sobre os direitos das mulheres. De fato, a peça é composta por seis monólogos para uma atriz e foi escrita em 1977, período de grande polarização entre direita e esquerda na Itália e em que ainda eram fortes as lutas emancipatórias iniciadas em 1968. O fio condutor é justamente a condição da mulher, a luta por maior igualdade. Os monólogos, em maior ou menor medida, têm um tom cômico, elementos épicos e relação com o contexto político italiano da época. Como diz Franca no prólogo ao espetáculo (RAME e Fo 2005: 12, tradução nossa),

faz dois mil anos que nós, mulheres, estamos chorando, e dessa vez vamos rir juntas e talvez até rir de nós mesmas; além disso, também porque um senhor que entendia muito de teatro, um certo Molière, dizia: "Quando você vai ao teatro e vê uma tragédia, você se identifica, participa, chora, chora, chora, depois vai pra casa e diz: como eu chorei bem essa noite!, e dorme relaxado. 0 discurso político passou por você como a água pelo vidro. Enquanto para rir é sempre Molière quem fala - é preciso inteligência, sutileza. A boca se escancara na risada, mas o cérebro também e, no cérebro, fincam-se os pregos da razão!

Traduzir os monólogos para o português foi desafiador por vários motivos, muitos dos quais podem ser agrupados no dilema: conciliar elementos antagônicos. Por um lado, como teoriza Henri Bergson (2020: 98), o

\footnotetext{
2 The Nobel Prize in Literature 1997. NobelPrize.org. Nobel Media AB 2020. Disponível em: https://www.nobelprize.org/prizes/literature/1997/summary/. Acesso 15 jan. 2021.

TradTerm, São Paulo, v.38, fevereiro/2021, p. 81-90

Número Especial - III JOTA

www.revistas.usp.br/tradterm
} 
riso se dá ao introduzir um elemento de estranhamento, em um elemento que é familiar ao público, quebrando a normalidade. Por outro, é importante manter na tradução as referências ao contexto político em que o espetáculo foi escrito, por ser fundamental para a poética da peça, ainda que distante do espectador. Portanto, é preciso manter o que é estranho ao espectador, bem como recriar também elementos familiares.

Neste trabalho, analisamos, não exaustivamente, três situações em que esse dilema se manifesta e apresentamos as escolhas tradutórias tomadas em cada caso, justificando-as. Para a tradução do humor, em particular, nos valemos de uma posição funcional, como a defendida por Marta Rosas (2003: 145) definimos o objetivo de provocar o riso e, a partir dele, decidimos como proceder na passagem para o português, acrescentando à posição funcional o critério de evitar trair o espírito, a poética do texto de Fo e Rame.

A primeira questão foi a tradução do título: em italiano, é um jogo de palavras que retoma a expressão milanesa 'tutta casa e chiesa', literalmente, 'toda casa e igreja', usada para indicar que uma mulher é respeitável e pudica, e introduz o elemento 'letto' [cama], indicador, pelo conteúdo da peça, da tensão entre a submissão sexual da mulher e a descoberta de sua sexualidade. Escolhemos traduzir por 'Bela, depravada e do lar' por achar que o termo 'bela, recatada e do lar', surgido em uma matéria da revista Veja (LINHARES 2016: 28) sobre Marcela Temer, mulher do presidente do Brasil na época, indica de forma parecida com a expressão 'Tutta casa e chiesa' uma mulher respeitável e pudica, modelo de submissão ao marido. Faltava, então, o elemento 'letto', que se deu com a troca de 'recatada' por 'depravada'.

É verdade que a escolha lexical em português indica mais a liberdade do que a submissão sexual, mas preferimos não usar a expressão cunhada por Linhares por considerá-la ligada a uma figura datada e pela falta do elemento de implosão dessa submissão, que é a sexualidade feminina. De toda forma, 'depravada' é uma palavra que aparece mais de uma vez no texto do espetáculo e a submissão sexual ainda pode ser evocada pela rima do título com a expressão 'Bela, recatada e do lar'. A escolha aproxima o espetáculo não apenas da realidade linguística brasileira, como também da realidade política.

TradTerm, São Paulo, v.38, fevereiro/2021, p. 81-90

Número Especial - III JOTA

www.revistas.usp.br/tradterm 
Certamente, devemos dosar esse tipo de domesticação (BERMAN 2007), mas, por outro lado, a própria poética da obra dos autores legitima esse tipo de procedimento: Rame e Fo raramente encenavam o mesmo texto, modificado quase todas as noites, em parte com improvisações, atualizado conforme o contexto político da cidade ou país em que apresentavam a peça.

O segundo caso, um trecho do prólogo trata da questão da linguagem, uma das discussões centrais do feminismo dos anos 1960-70. Para mostrar como a nossa linguagem é repleta de termos relacionados principalmente à sexualidade masculina, Franca Rame recita uma poesia contendo nomes de órgãos sexuais masculinos e compara a uma poesia com palavras ligadas à sexualidade feminina. Nas primeiras leituras da obra italiana, parecia-nos uma paródia, mas não conseguimos identificar o texto de partida, provavelmente, ligado à tradição escolar italiana. Sendo assim, achamos que um dos elementos do riso, o estranhamento, estava garantido com a introdução de termos sexuais em trechos tidos como solenes, que soam como clássicos, mas que a tradução literal para o português ainda não daria conta da familiaridade necessária para a identificação com o público, nem quebraria a expectativa. Por isso, escolhemos traduzir mantendo os mesmos termos relacionados à sexualidade, mas parodiando textos que fossem capazes de provocar, no Brasil, a sensação de familiaridade.

Quadro 1 - Comparação de parte do prólogo: texto de partida e texto de chegada (MELLO 2019:101-102)

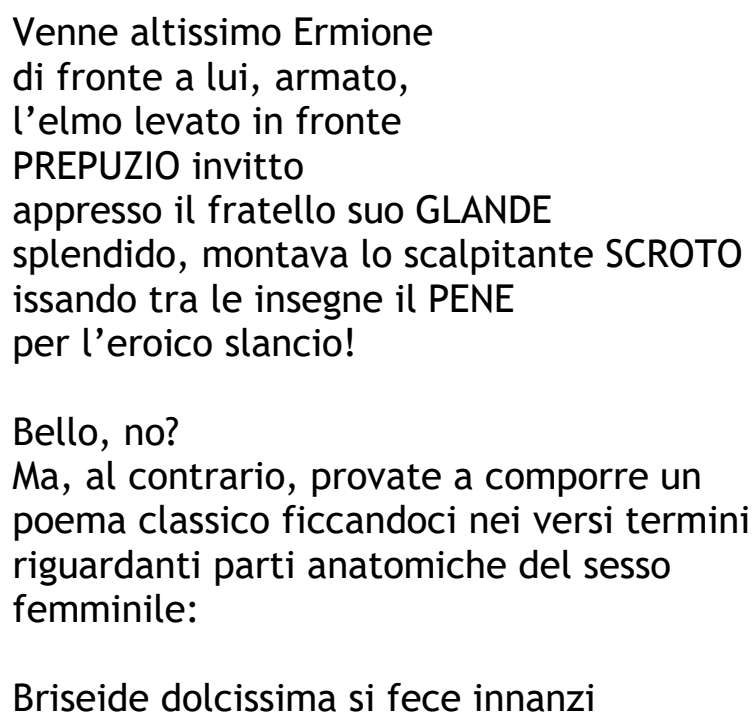

Briseide dolcissima si fece innanzi

"Ora (direis) ouvir PREPÚCIOS! Certo perdeste o senso!" E eu vos direi, no entanto, Que, para ouvi-los, muita vez desperto E ergo o PÊNIS, pálido de espanto... E conversamos toda a noite, enquanto A Via Láctea, como uma GLANDE aberta, Cintila. E, ao vir do sol, saudoso e em pranto, Inda os procuro pelo ESCROTO deserto.

Bonito, né?

Mas, ao contrário, tentem compor um poema romântico enfiando nos versos termos que dizem respeito às partes anatômicas do sexo feminino:

Minha terra tem clitóris 
e con lei, amata dal Pelide, infuriata clitoride...

No, non funziona. Ci hanno appioppato dei termini orribili!
Onde canta o útero

Os ovários que aqui gorjeiam

Não gorjeiam como lá

Não, não funciona. Nos rotularam com termos horríveis!

Há, também, a possibilidade de o texto parodiado ter origem religiosa, por exemplo, a palavra 'altissimo' no primeiro verso, o que o tornaria altamente blasfemo. Pensando que, na Itália, a presença da Igreja Católica como instituição (e como Estado) é muito mais forte do que no Brasil (e era ainda mais nos anos 1970), e que a blasfêmia é um hábito cultural italiano, mas não brasileiro, não nos parece inadequado diminuir a força do possível ataque à fé católica nesse trecho usando como elemento familiar dois textos da literatura canônica brasileira, as poesias Ora (Direis) Ouvir Estrelas (1902), de Olavo Bilac e Canção do Exílio (1846) de Gonçalves Dias.

Nos dois primeiros casos citados, a estratégia tradutória é algo domesticadora, embora tenha tentado manter o espírito crítico e derrisório da obra dos italianos. O último caso do qual trataremos, porém, é diferente. Um dos monólogos, La Mamma Fricchettona, é mais ligado à política especificamente italiana da década de 1970. Possui, portanto, implícitos culturais, definidos por Peeter Torop (2010: 115), como elementos tidos como óbvios na cultura do texto de partida, mas não sempre na cultura receptora. Por isso, a escolha sobre qual tipo de tradução fazer foi mais difícil.

Por um lado, a tradução brasileira usada nos palcos, assinada por Roberto Vignati e Michele Piccoli, Brincando em cima daquilo (1984), ${ }^{3}$ perdera as alusões mais específicas ao contexto político; por outro lado, traduzir o texto literalmente poderia comprometer o entendimento do público,

Pensamos, inicialmente, em traduzir adaptando para o contexto político brasileiro, mas chegamos à conclusão de que o papel de modificar estruturalmente o texto cabia mais aos diretores e encenadores do que à tradutora, pensando também na longevidade da tradução. Por isso, decidimos

\footnotetext{
${ }^{3} 0$ texto consultado é uma cópia datilografada, disponível no acervo da Sociedade Brasileira
} de Autores de Teatro.

TradTerm, São Paulo, v.38, fevereiro/2021, p. 81-90

Número Especial - III JOTA

www.revistas.usp.br/tradterm 
manter quase todas as referências à situação política italiana da época, escolhendo, para isso, segundo a terminologia de Torop (2010), a estratégia de realizar, além de uma tradução textual - a tradução de um texto inteiro em outro texto inteiro -, também uma tradução metatextual (ou seja, a tradução de um texto em uma cultura, fazendo uso de instrumentos metacomunicativos).

O resultado de tal estratégia foi a inserção de um prólogo, introduzindo o monólogo traduzido. Embora essa estratégia aumente o tamanho do texto de chegada, reproduz uma característica recorrente no teatro épico de Rame e Fo, a utilização de prólogos predominantemente narrativos explicando os monólogos, predominantemente representativos (MELLo 2019: 133). Além disso, essa estratégia dá mais liberdade aos responsáveis pela encenação da peça, uma vez que, ao acessarem o tema e o contexto de produção da obra, podem escolher de modo mais consciente como encenar o espetáculo. 0 monólogo elaborado, também busca recriar estratégias de crítica e de humor da obra dos italianos, como pode ser lido abaixo:

O próximo monólogo, A mamãe esquisitona, é o mais difícil de entender, porque ele se passa num contexto muito diferente do nosso, a Itália da década de 70 . Imaginem... uma mãe de esquerda, que tem um marido de esquerda, um filho de esquerda... e mesmo assim tem que dar conta sozinha do trabalho doméstico. Estranho, né? Além disso, a esquerda dos pais e a esquerda do filho são diferentes e não se dão muito bem... os pais são comunistas ortodoxos do Partido Comunista Italiano, o $\mathrm{PCl}$. Isso quer dizer que eles são revolucionários... dentro da lei. Que eles querem acabar com o sistema... participando das eleições. Que eles acham que a religião é o ópio do povo... E fazem acordo com a Democracia Cristã, a DC, que era o partido mais importante na época, um partido católico.

Mas são as necessidades da conjuntura, é claro. Ainda tinha guerra fria, esquerda e direita, comunismo e capitalismo, essas coisas fora de moda. Nos anos 70, quando a esquerda era muito de esquerda, a direita respondia sendo muito de direita. E vice-versa. No Chile, por exemplo, o Allende foi eleito em 1970. Aí em 1973 a direita respondeu com um golpe, matando Allende e colocando o Pinochet no poder. Hoje as coisas mudaram, não precisa mais matar ninguém. É só fazer um acordo... com o Supremo, com tudo. Mas na época era mais difícil, porque a população acompanhava a política muito de perto, ia pra rua e tal. E na Itália eles tinham muito medo de que algo parecido com o Chile pudesse acontecer, porque o clima do país estava tenso mesmo. Era o caos, atentado atrás de

TradTerm, São Paulo, v.38, fevereiro/2021, p. 81-90

Número Especial - III JOTA

www.revistas.usp.br/tradterm 
atentado, e até hoje não dá pra saber direito o que aconteceu... se esse atentado foi a extrema esquerda quem fez, se aquele outro foram os fascistas... mas tem gente que acha que o que aconteceu foi muito bem planejado, internacionalmente, inclusive pela Otan. O nome já diz muita coisa: "estratégia da tensão". Que é, basicamente, tocar o terror para as pessoas ficarem com medo. E quem tem medo costuma ser mais conservador...

Foi assim que aconteceu o famigerado "compromisso histórico": o Berlinguer, líder do $\mathrm{PCl}$, resolveu se aproximar da DC em 1973 para garantir que a Itália continuasse a ser uma democracia, e a partir de 1976 começaram os governos de coalizão. Essa parte é fácil de entender, no Brasil a gente tá mais que acostumado com aliança da esquerda com a igreja, com o centro, com a direita... Mas essa coisa da religião católica na Itália era mais séria ainda, porque até 1984 o catolicismo era a religião oficial do Estado e quem pagava o salário dos padres era a Itália, não o Vaticano. Hoje ainda tem isenção fiscal, que nem aqui, mas a coisa já melhorou um pouco.

Enfim, voltando pro compromisso histórico, teve um monte de gente que ficou insatisfeito, porque na prática isso queria dizer que o governo tinha menos oposição. E aí a vida tá ruim, o salário tá baixo, a inflação começa a subir vertiginosamente... mas o governo não faz nada. E a oposição não reclama. Foi aí que muita gente resolveu que era hora de agir por conta própria, de deixar os partidos de lado. Era dessa esquerda que o filho da mamãe esquisitona fazia parte. Uma esquerda criativa, herdeira do movimento hippie, que se chamava de freak ou de índio metropolitano, que ouvia rock, ia pra rua... e criticava o $\mathrm{PCl}$.

As pessoas nessa época eram criativas mesmo. Vou dar só um exemplo. Quem tem mais de 40 anos deve se lembrar da inflação dos anos $80 .$. Era receber o salário e ir correndo pro supermercado, comprar o máximo de coisa possível, porque um dia depois, ou até no mesmo dia, o preço de todos os produtos ia aumentar. Foi assim na Itália a partir de 1974. Pra vocês terem ideia, teve um dia que acabou o macarrão no supermercado. Na Itália!!! acabou!!! o!!! macarrão!!! Isso porque anunciaram um aumento de $50 \%$, então todo mundo foi correndo comprar o máximo de macarrão possível antes de o preço subir. Ao invés de ficar estocando comida, teve gente que teve uma ideia melhor: a autorredução ou o autodesconto. Você vai no supermercado, faz a sua compra normalmente e paga o valor que achar justo, com um desconto de $50 \%$, por exemplo. Ótima ideia, né?

Vou começar (MELLO 2019: 133-135).

Esperamos, assim, ter recriado o objetivo didático do teatro de Dario e Franca, agindo não apenas como tradutores, mas também como atores que interpretam o papel dos dramaturgos italianos. Tereza Virgínia Ribeiro

TradTerm, São Paulo, v.38, fevereiro/2021, p. 81-90

Número Especial - III JOTA

www.revistas.usp.br/tradterm 
Barbosa (2014: 31) já havia refletido a respeito da semelhança entre o papel do tradutor e aquele dos profissionais do teatro:

se Phyllis Zatlin (2005) [...] atribui ao tradutor a função de dramaturgo, propomos, para a teoria da tradução, algo um pouco mais amplo (já que o dramaturgo se limita à escrita); postulamos para o tradutor o papel de ator, dramaturgo e diretor ao mesmo tempo. Enquanto ator, ele marca o texto traduzido com sua personalidade, ideologia e corpo; enquanto dramaturgo, ele translada as estratégias de teatro na costura de seu texto (com isso, evidentemente, altera a sintaxe, a pontuação, as lacunas dos subentendidos etc.), e enquanto diretor, ele elabora (por causa de suas escolhas lexicais e sintáticas, de remanejamentos e manipulações, de ênfases, de tons etc.) uma proposta de espetáculo-cultural-virtual ou, em outros termos, de situação de acontecimento do evento textual.

Além disso, acreditamos que não domesticar demasiadamente o texto é também tratar eticamente o público e os profissionais responsáveis pela encenação do texto, reconhecendo seu intelecto. Certamente, a plateia pode entender algo que não conhece bem a fundo e os atores, diretores e encenadores elaborarão estratégias além da tradução para se comunicar com os espectadores. Por fim, como ressalta Umberto Eco (2007: 426), “entre os sinônimos de fidelidade não está a palavra exatidão. Lá estão antes lealdade, honestidade, respeito, piedade”. Não procuramos a exatidão ou a literalidade ao traduzir o texto italiano, mas interpretamos o texto fonte "com apaixonada cumplicidade" e nos empenhamos em "identificar aquilo que, para nós, é o sentido profundo do texto" e em “negociar a cada instante a solução que nos parece mais justa” (ECO 2007: 426). Justiça que é, aliás, elemento fundamental da obra de Rame e Fo.

TradTerm, São Paulo, v.38, fevereiro/2021, p. 81-90

Número Especial - III JOTA

www.revistas.usp.br/tradterm 


\section{Referências}

Barbosa, T. V. R. 0 tradutor de teatro e seu papel. Itinerários, n. 38, Araraquara, 2014, pp. 27-46. Disponível em: https://periodicos.fclar.unesp.br/itinerarios/article/view/7212. Acesso em: 15 jan. 2021.

Bergson, H. O riso: Ensaio Sobre o Significado do Cômico. Trad. Maria Adriana Camargo Cappello. São Paulo: Edipro, 2020.

Berman, A. A Tradução e a Letra, ou o Albergue do Longínquo. Trad. MarieHélène Catherine Torres; Mauri Furlan; Andréia Guerini. Rio de Janeiro: 7Letras/PGET, 2007.

Eco, U. Quase a mesma coisa: Experiências de Tradução. Trad. Eliana Aguiar. Rio de Janeiro: Record, 2007.

LINHARES, J. Marcela Temer: bela, recatada e “do lar”. Veja, São Paulo, n. 2474, p. 28, 21 abr. 2016.

Mello, A. B. Bela, depravada e do lar: como traduzir(am) Tutta casa, letto e chiesa, de Franca Rame e Dario Fo, no Brasil. 2019. 195p. Dissertação (Mestrado em Letras: Estudos Literários) - Faculdade de Letras, Universidade Federal de Minas Gerais, Belo Horizonte, 2019.

Rame, F.; Fo, D. Tutta Casa, Letto e Chiesa. Milão: Fabbri Editori, 2006.

Rame, F.; Fo, D. A mãe Porra Louca. Trad. Michele Piccoli e Roberto Vignati. Rio de Janeiro: s. e., 1984.

Rosas, M. Por uma teoria da tradução do humor. D.E.L.T.A., n. 19, p. 133-161, 2003. Disponível em: http://www.scielo.br/pdf/delta/v19nspe/09.pdf . Acesso em: 15 jan. 2021.

Nobel Prize. The Nobel Prize in Literature 1997. NobelPrize.org. Nobel Media AB 2020. Disponível em:

https://www. nobelprize.org/prizes/literature/1997/summary/.

Acesso 15 jan. 2021.

TOROP, P. La traduzione totale: Tipi di Processo Traduttivo nella Cultura. Edizione italiana a cura di Bruno Osimo. Milão: Hoepli, 2010.

Recebido em: 30/03/2020

Aceito em: 22/09/2020

Publicado em fevereiro de 2021

TradTerm, São Paulo, v.38, fevereiro/2021, p. 81-90

Número Especial - III JOTA

www.revistas.usp.br/tradterm 